\title{
Culturas de escola e celebração da excelência: cartografia das distinções em Portugal
}

Leonor Lima Torres

I- Universidade do Minho (UM),

Braga, Portugal

Contato: leonort@ie.uminho.pt

\section{Resumo}

As orientações de política educativa de âmbito global têm colocado no centro das suas prioridades a promoção da excelência, da qualidade e da eficácia dos sistemas de ensino e formação. Este texto propõe-se a debater o impacto dessa agenda na realidade educativa portuguesa a partir de um olhar sobre a política em estado prático, isto é, sobre os mecanismos de apropriação ocorridos no espaço organizacional e sua articulação com as especificidades culturais da escola. À luz desse enfoque, pretende-se compreender de que forma a cultura de escola redefine localmente a sua missão educativa, ajustando-a aos propósitos democráticos e igualitários e/ ou às exigências de promoção da excelência e do mérito. Partindo da hipótese de que as dimensões culturais exercem um papel central na recontextualização das políticas educativas, procurou-se identificar, no sistema educativo português, o alcance de um dos rituais mais expressivos da missão da escola: os rituais de distinção dos melhores alunos. Da análise de conteúdo efetuada em cerca de 1500 documentos produzidos no contexto das escolas públicas com ensino secundário, resultou um mapeamento nacional dos rituais de distinção. As conclusões apontam para uma forte adesão das instituições com ensino secundário aos rituais de distinção ou de reconhecimento público do mérito. Contudo, nem a sua configuração nem os critérios de seleção apresentam um caráter uniforme, o que nos aponta para a existência de distintas conceitualizações de excelência, decorrentes das diferentes culturas de escola e do seu papel na defınição da sua política e do seu critério de sucesso.

\section{Palavras-chave}

Cultura de escola - Excelência - Distinção - Escola pública 


\title{
School culture and the celebration of excellence: mapping distinctions in Portugal
}

Leonor Lima Torres'

\begin{abstract}
Global educational policy guidelines have placed at the center of their priorities the promotion of excellence, quality and efficiency of education and training systems. This text intends to discuss the impact of this agenda on the Portuguese educational reality by examining the policy in practical state, that is, appropriation mechanisms in the organizational space and their relationship with the cultural specificity of the school. In the light of this approach, I intend to understand how the school culture locally redefines its educational mission, adjusting it to the democratic and egalitarian purposes and/or to requirements of promoting excellence and merit. Assuming that the cultural dimensions play a central role in the recontextualization of educational policies, I have sought to identify in the Portuguese education system the scope of one of the most significant rituals of the school's mission: the rituals of distinction of the best students. Following the content analysis of about 1500 documents produced in the context of public schools with secondary education, I have made a national mapping of distinction rituals. The findings point to a strong adherence of institutions with secondary education to rituals of distinction or of public recognition of merit. However, neither its configuration nor its selection criteria have a uniform character, which indicates the existence of different concepts of excellence, which result from the different school cultures and their role in defining each school's policy and success criteria.
\end{abstract}

\section{Keywords}

School culture - Excellence - Distinction - Public school.

I- Universidade do Minho (UM),

Braga, Portugal

Contact: leonort@ie.uminho.pt 


\section{Introdução}

A crescente pressão dos sistemas escolares para a produção de resultados sobressai visivelmente como ideia dominante em diversos estudos desenvolvidos, sobretudo nos contextos europeu e americano. As organizações escolares encontram-se num espaço-tempo de dupla compressão: por um lado, condicionadas por políticas educativas de inspiração gerencialista e, por outro, pressionadas pelas famílias e comunidades locais para a promoção do sucesso educativo. Esse movimento simultâneo e convergente tem vindo, paulatinamente, a reconfigurar as prioridades da escola pública, empurrando-a para a valorização cada vez mais assumida dos valores da eficácia, da excelência e da performatividade, deixando na penumbra a sua missão inclusiva e democrática.

Vários grupos de pesquisa têm vindo a colocar no centro da agenda investigativa o estudo do dilema mais-melhor escola ou, por outras palavras, a relação de forças entre os mandatos democrático e meritocrático da escola pública. A realidade francesa tem tomado a dianteira da produção científica e animado o mercado editorial com um vasto leque de trabalhos, como, por exemplo, Laval (2004), Hirtt (2005), Van Zanten (2000, 2009), DuruBellat (2006, 2009), Baudelot e Establet (2009), Dubet (2010). No outro lado do Atlântico, a publicação da coletânea Equity and excellence: towards maximal learning, opportunities for all students (BRANDEN; AVERMAET; HOUTTE, 2011) irrompe com vários estudos que procuram aprofundar a atual situação dos sistemas educativos perante a dupla missão de promover a inclusão e a excelência. No contexto da realidade portuguesa, essa problemática tem vindo timidamente a despontar as atenções investigativas, embora o seu estudo seja ainda parcelar e pouco sistemático (TORRES; PALHARES, 2014).

A expressão mais clara de que estamos perante uma "radicalização do mandato neomeritocrático" (AFONSO, 2013) é a adesão alargada das instituições escolares portuguesas a práticas de distinção dos melhores alunos, um prenúncio de que "on est ainsi entré dans une culture anxieuse du résultat" 1 (BAUDELOT; ESTABLET, 2009, p. 9). Os rituais de distinção recobrem múltiplas manifestações carregadas de valor simbólico no processo de socialização das jovens gerações numa cultura marcadamente performativa. Este artigo visa justamente a refletir sobre a amplitude e as gradações das práticas de distinção acadêmica nas escolas e agrupamentos de escolas com ensino secundário em Portugal, recorrendo a resultados preliminares de um projeto de investigação sobre a problemática da excelência acadêmica nas escolas públicas portuguesas². Definiu-se como objetivo de pesquisa mapear os rituais de distinção em nível nacional ${ }^{3}$, a fim de conhecer o seu impacto na regulação da vida das instituições escolares.

Do ponto de vista formal, a possibilidade de reconhecer e premiar os melhores alunos através da instituição de quadros de valor e de excelência ${ }^{4}$ encontra-se regulamentada em Portugal desde 1990, tendo vindo a ser reforçada, de forma avulsa, em sucessivos diplomas, designadamente no Estatuto do aluno e ética escolar (Lei no. 51/2012, de 5 de setembro). Contudo, as instituições escolares foram resistindo à sua implementação, alegando,

1- Em português, "entramos, assim, numa cultura ansiosa pelos resultados" (BAUDELOT; ESTABLET, 2009, p. 9, tradução nossa).

2- Este trabalho é financiado por fundos nacionais através da Fundação para a Ciência e a Tecnologia (FCT), no âmbito do projeto PTDC/IVC PEC/4942/2012 do Centro de Investigação em Educação da Universidade do Minho (CIEd), intitulado Entre mais e melhor escola: a excelência académica na escola pública portuguesa.

3- 0 incremento dos rituais de distinção dos melhores alunos nas escolas públicas portuguesas constitui um fenômeno recente e pouco estudado. Esses rituais de celebração são da iniciativa de cada escola, podendo apresentar diferentes graus de formalização (com ou sem cerimônia pública), variados formatos (quadros de excelência, quadros de valor, prêmios de mérito), formas de divulgação (local, regional, nacional) e premiação (entrega de diploma, prêmio pecuniário, recompensas simbólicas).

4- Os quadros de valor e de excelência criados pelo Despacho Normativo $n^{0}$. 102/90, de 12 de setembro, "destinam-se a tornar patente 0 reconhecimento de aptidões e atitudes dos alunos ou grupos de alunos do $2^{\circ}$ e $3^{\circ}$ ciclos do ensino básico e do ensino secundário, público, particular ou cooperativo, que tenham evidenciado valor e excelência nos domínios cognitivo, cultural, pessoal ou social, bem como a atribuir prémios, em casos específicos e excepcionais" (capitulo I, artigo 1²) 
entre outras razões, tratar-se da recuperação do tradicional quadro de honra dos liceus de antes do 25 de Abril, associado à escola do fascismo e, segundo Cunha (1997), perspectivado como um instrumento "[...] reducionista nos seus objetivos, ideológico nos seus requisitos, elitista nos seus resultados" (p. 103).

Entretanto, à medida que o avanço das políticas neoliberais se foi intensificando, as organizações escolares entraram num ciclo avaliativo sem precedentes, sendo progressivamente pressionadas a alterar os seus modos de gestão e as suas prioridades estratégicas. É nesse contexto de profunda mutação das formas de regulação política que as escolas começam a adotar progressivamente dispositivos de premiação do mérito, muito embora de formas diferenciadas em função da sua matriz identitária. De forma a compreender sociologicamente o processo de penetração da ideologia meritocrática no sistema escolar português, apresenta-se, na primeira parte deste texto, um modelo de análise que procura articular as diferentes dimensões da cultura da escola com os modos de operacionalização das orientações políticas de âmbito global, nacional e local. Apesar de sobredeterminada por circunstâncias políticas e sociais, a ritualização da distinção ocorre em contextos escolares culturalmente diferenciados, sendo indispensável discutir a sua natureza plural e compósita.

\section{As diferentes faces das culturas de escola}

A expansão de políticas educativas de natureza gerencialista tem vindo a repercutir-se deforma insinuantenos modos de funcionamento das instituições escolares. Quer se perspective o advento de uma regulação de tipo pósburocrático (BARROSO, 2005) quer se rebata a presença de uma agenda hiperburocrática (LIMA, 2012), o certo é que as modalidades de regulação da educação encontram-se em profunda mutação. Em qualquer dos casos, essa corrente racionalizadora, mais do que induzir uma uniformização do sistema escolar, tem posto em evidência a sua natureza diferenciadora, compósita e plural, revelando o quanto as dimensões culturais e simbólicas se interpõem entre o sistema educativo (estrutura) e o ator escolar (ação). A constituição de megaagrupamentos ${ }^{5}$, a implementação de lideranças unipessoais $^{6}$, a disseminação de diferentes modalidades de prestação de contas (programas de avaliação externa, dispositivos de avaliação internacional, avaliação de desempenho profissional, monitorização dos planos de melhoria, publicitação de rankings, reforço dos suportes informáticos de controle), entre inúmeras outras medidas de política educativa focadas nos resultados, têm pressionado as diversas instituições escolares à reprodução de uma cultura escolar de tipo integrador e performativo, numa lógica reprodutiva topdown. Se é certo que essa cultura escolar, entendida como padrão normativo dominante, constitui uma matriz de referência nacional (mesmo que subordinada aos imperativos globais), na verdade, os processos de escolarização ocorrem em espaços-tempo muito diferenciados e frequentemente dominados por lógicas e dinâmicas locais difíceis de enquadrar naquela moldura política. A apropriação da cultura escolar ocorre sempre em contexto, seja ele restrito à escola/estabelecimento de ensino,

5 - Por força da imposição jurídico-formal, o processo de reorganização e racionalização da rede escolar em Portugal intensificou-se a partir de 1998 com a constituição dos agrupamentos de escolas de tipo vertical e horizontal, subordinados a uma única direção situada na escola-sede. A maioria desses agrupamentos assumiu um formato vertical, integrando todos os níveis e ciclos de educação e ensino, desde a educação préescolar ao ensino secundário. Nos últimos cinco anos, foram constituídos os mega-agrupamentos, que resultaram da integração de agrupamentos verticais já anteriormente constituídos até ao $3 .^{\circ}$ ciclo do ensino básico, com escolas secundárias que eram, até esse momento, escolas não agrupadas. De acordo com a Portaria n. ${ }^{\circ} 30 / 2014$, de 5 de fevereiro, a rede escolar passa a ser constituída por 712 agrupamentos de escolas, 98 escolas não agrupadas e 120 escolas de $1 .^{\circ}$ ciclo do ensino básico.

6- Durante mais de três décadas (1974-2008), o principal órgão de gestão e administração das escolas básicas e secundárias e, mais tarde, dos agrupamentos de escolas, foi democraticamente sufragado pelos pares da comunidade escolar, configurando um órgão colegial. A partir de 2008, com a publicação do Decreto-lei $n^{0} 75 / 2008$, de 22 de abril, implementouse um modelo unipessoal de gestão, centrado na figura do diretor, que passou a ser eleito pelo conselho geral, órgão que integra representantes da comunidade educativa, metade dos quais são professores. 
seja alargado ao agrupamento de escolas e suas interações com a comunidade envolvente. Estáse a ver, pois, que a compreensão dos processos de recontextualização política não pode dispensar a análise das culturas organizacionais.

Uma abordagem em escala mesoanalítica, focada no contexto da organização escolar, permitiu destrinçar dois cenários culturais já enunciados em trabalhos anteriores (TORRES, 2004, 2010), mas agora retomados para efeitos de enquadramento do trabalho de campo apresentado neste artigo.

0 primeiro cenário, designado cultura organizacional da escola/agrupamento (cultura organizacional escolar ou cultura de escola) constitui uma categoria central para a abordagem das políticas em ação ou, por outras palavras, das práticas geradas pelo uso quotidiano das políticas. A cultura da organização é ao mesmo tempo: a) nuclear, porque está no centro e na periferia da ação educativa; b) transversal, na medida em que condiciona todas as outras micropolíticas; c) transgeracional, atendendo a que os seus efeitos não se esgotam no curto espaço de tempo; e, de forma expressiva, d) estruturante, pois os seus efeitos prolongam-se no médio e longo prazo. A perenidade é, porventura, o atributo mais marcante dos fenômenos culturais: os valores, as ideologias e as crenças representam, na ótica de vários autores, como Schein $(1985,1991)$ Martin (1992, 2002), Alvesson e Berg (1992), Prosser (1999) e novamente Alvesson (2002), os pressupostos básicos da cultura, desenvolvidos e sedimentados nas memórias coletivas num horizonte temporal de longa duração. Porém, no caso específico das organizações escolares, onde se verifica uma significativa renovação anual de atores (professores, alunos, pais), a cultura instituída convive regularmente com novos desafios, exigindo dos atores uma dinâmica constante de ajustamentos culturais. Em termos genéricos, a categoria cultura organizacional escolar reporta-se aos processos de recontextualização da ordem política prescrita e estabelecida (cultura escolar) ocorridos em cada escola consoante os jogos sociais e de poder que se estabelecem entre os atores, plasmados em práticas e dinâmicas organizacionais concretas, mas de natureza circunstancial e adaptativa.

0 segundo cenário, teoricamente adjacente e sobreposto ao anterior, dá conta de uma realidade cultural mais perene, mais estruturante e estruturadora da organização escolar. Os valores e as crenças enraizadas nas lógicas de ação educativa produzem, na longa duração, fenômenos de identidade organizacional, que funcionam como motor e resguardo da cultura instituída. As regularidades culturais e os rastos sedimentares daqui decorrentes configuram uma outra concepção de cultura: cultura organizacional de escola, que tende a erigir-se num modelo significativo de ação, construído sobretudo na informalidade e que tende a perpetuar-se no tempo para além e através da cultura organizativa imposta ou recriada no contexto escolar. Esse tipo de cultura representa os modos de ser e de fazer coletivamente construídos, que ultrapassam e estão para além das orientações normativas e estruturais e, por essa razão, ela tende a funcionar como agência reguladora da ação.

Essa tríplice categorização deve ser entendida como um dispositivo hermenêutico fundamental, uma espécie de propulsor de um novo olhar sobre as dinâmicas escolares, sem qualquer imputação de hierarquias ou sequências lógicas. A compreensão do todo cultural por via da interpretação das suas singularidades exige, entretanto, a exploração das seguintes questões: a) como se constrói e desenvolve a cultura no espaço organizacional?; b) qual o grau de partilha da cultura entre os atores escolares? Enquanto a primeira questão subentende a multiplicidade de fatores que intervêm na sedimentação de uma dada cultura, destacando a centralidade de determinados processos de socialização no desenvolvimento de uma identidade organizacional, a segunda aponta para a pluralidade de manifestações culturais coexistentes na organização e o grau 
de identificação dos atores com os modelos de gestão e liderança. Embora interligados, esses dois vetores constituem os pilares estruturantes da problemática da cultura.

Mesmo correndo o risco de simplificar a complexidade da realidade cultural, o gráfico 1 procura ilustrar, em jeito de dispositivo analítico, o processo de construção da cultura à luz das categorias acima aludidas. Entende-se a cultura como um processo dinâmico construído a partir da interação entre inúmeros fatores de natureza diversa, ora mais próximos da estrutura formal (sistema), ora diluídos no espaço da informalidade, sendo que, em ambos os casos, poderão ainda emergir de contextos internos ou externos à própria instituição. Da relação de tensão entre os vários polos (estrutura/ação; dentro/fora), resultam distintos cenários culturais, uma espécie de ideais-tipos (no sentido weberiano) esquematicamente identificados nesta bússola interpretativa: o cenário 1 traduz a presença da cultura escolar construída na esfera pública (nacional e transnacional) e difundida em escala global; o cenário 2 enuncia a influência da cultura socioprofissional resultante do processo de aprendizagem social e profissional dos atores escolares desenvolvido nos mais diversos contextos de socialização não escolar; o cenário 3 reporta-se à cultura organizacional escolar construída no espaço organizacional de cada estabelecimento de ensino, refletida em regras e mecanismos de adaptação situacional à conformidade burocrática; o cenário 4 remete para a cultura organizacional de escola, expressa pelo modus operandi historicamente instituído e conferidor da identidade organizacional.

$\mathrm{Na}$ realidade, as várias faces da cultura aqui enunciadas interpenetram-se e sobrepõemse, sendo ao mesmo tempo janela e espelho: abrem-se a vários ângulos de observação, destapando as regularidades e as idiossincrasias e, em simultâneo, projetam a imagem identitária da instituição. As diferentes relações de forças que se estabelecem entre essas faces dão conta da essência dos processos culturais na sua globalidade em cada organização escolar em concreto. Para além da apreensão do ethos cultural, resultante das sinergias entre as quatro faces culturais, importa aprofundar o grau de consistência da cultura em cada escola, expresso na segunda questão acima levantada. Retomando aqui as três perspectivas propostas por Martin (1992, 2002)integradora, diferenciadora e fragmentadora-, importa reforçar a ideia de que a cultura da organização escolar pode refletir, no seu todo, diferentes tipos de manifestação, ainda que seja possível, na maioria das situações, identificar a manifestação dominante.

Gráfico 1 - Processo de construção da cultura de acordo com as diversas faces

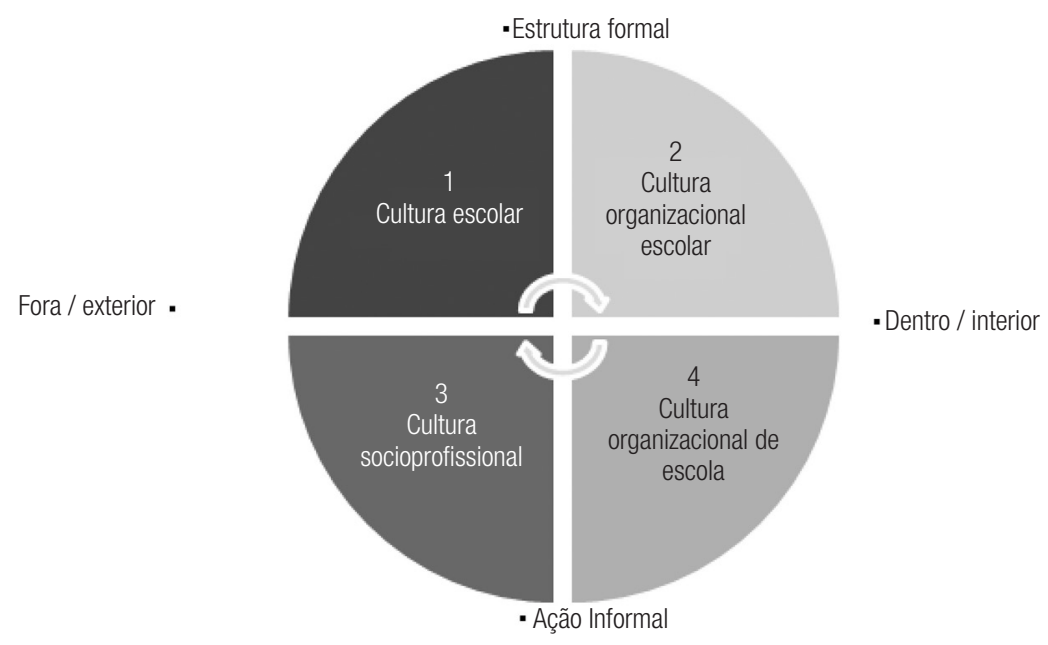


0 atual modelo de governação das organizações escolares, assente em novas modalidades de controle e prestação de contas ${ }^{7}$, veio acentuar a descontinuidade entre a cultura escolar que se pretende instituir em escala nacional e a cultura organizacional de escola quotidianamente desenvolvida em contexto. Pressionadas à conformidade burocráticopolítica, as lideranças unipessoais centradas na figura do diretor revelam-se frequentemente em tensão com as lógicas pedagógicas, corporativas e profissionais características do espaço escolar. Nessas situações de adversidade cultural, as singularidades de cada escola tendem a emergir com mais força e expressividade.

À luz do modelo analítico ilustrado no gráfico 1, admite-se a existência de diferentes graus de aproximação entre a cultura organizacional de escola e a cultura escolar a primeira pode apresentar diferentes modos de articulação com a segunda. No quadro dessa interseção, os processos de liderança jogam um papel fundamental enquanto artífices do poder, pois, na verdade, refletem a cultura organizacional de escola, mas também agem sobre ela. No plano hipotético, os processos de liderança podem afirmar-se ora como reprodutores da cultura escolar, ora como guardiões da cultura organizacional de escola, ora como mediadores ou entrepostos culturais, uma espécie de agentes de recontextualização cultural.

\section{A política em estado prático}

Abordar sociologicamente as políticas educativas de um determinado espaço-tempo social constitui um exercício analítico tanto difícil quanto desafiador, sobretudo quando se procura escapar aos rígidos dualismos e simetrias que põem em confronto diferentes planos e escalas de análise (macro-micro, interior-exterior, estrutura-ação). No panorama

7- Entre os inúmeros dispositivos de controle e prestação de contas que regulam o funcionamento das instituições escolares, destacam-se os programas de avaliação externa das escolas, as diversas intervenções por parte da Inspeção Geral da Educação e Ciência, a divulgação dos rankings das escolas e a implementação de plataformas de gestão informática. investigativo português, privilegiam-se, por um lado, as abordagens macroanalíticas voltadas para o estudo de regularidades e tendências, incidindo sobre certas reformas e medidas políticas de maior impacto no sistema educativo, e, por outro lado, as abordagens de alcance meso e microanalítico focadas nos efeitos que essas medidas exercem nos processos organizacionais e pedagógicos. Neste texto, propomos um olhar focado no efeito compósito que as diversas orientações políticas podem gerar nas dinâmicas escolares.

Um acompanhamento regular das orientações de política educativa produzidas em Portugal nas últimas décadas revela-nos o quanto elas evidenciam, no seu conjunto e conjuntura, a ideia de desconexão e fragmentação. Os vários diplomas difundidos pelo poder central e difundidos em escala nacional estão longe de constituir um corpo de orientações coerente e homogéneo, que teria por referência uma matriz política claramente definida. As dissonâncias e contradições de sentido e conteúdo, resultantes das complexas relações entre dispositivos de ação pública, conhecimento e política (BARROSO, 2003, 2006; BARROSO; CARVALHO, 2012; CARVALHO, 2011), tendem a gerar mecanismos de apropriação difusos, circunstanciais e sempre mediados pelas especificidades culturais de cada instituição. Confrontados com a necessidade de implementar medidas avulsas que se inscrevem em distintas tonalidades políticas e que derivam de complexos jogos de poder, os atores escolares vão efetuando ajustamentos sucessivos à realidade cultural, numa tentativa de reunir e conferir coerência a lógicas de ação frequentemente descompassadas. Paradoxalmente, a pretensa padronização das orientações legais tende a gerar no espaço escolar o retraimento e a fragmentação progressiva da experiência, por via da incorporação de disposições cruzadas e justapostas. Essas disposições, fortemente vinculadas à memória coletiva de um passado cultural enraizado, vão reunindo os fragmentos, ao mesmo tempo que reavivam costumes e tradições. 
0 processo de incorporação e de realização da ação educativa tende a produzir, dentro dos limites espaço-temporais restritos de cada escola, um efeito compósito, uma espécie de injunção política de terceira dimensão. Essa configuração política singular resulta, assim, de um processo de mediação não linear entre a ordem política e normativa de âmbito central e global (primeira dimensão) e a sua circulação e recepção em contexto organizacional (segunda dimensão). Por seu turno, as experiências e vivências quotidianas, fortemente condicionadas pela cultura sedimentada na instituição, constituem momentos propícios à ativação e formação de uma configuração política em estado prático (terceira dimensão). Essa reatualização e reinvenção da ordem política, agora ajustada e recontextualizada ao espaço social da escola/agrupamento, surge aos olhos do investigador como uma outra realidade que, apesar de implícita, estipula novos horizontes de referência e novos padrões de orientação para a ação. Consoante as dinâmicas empreendidas em cada instituição, as práticas organizacionais podem incorrer numa dupla infidelidade, ao divergirem ora da agenda política nacional ora das orientações locais plasmadas no projeto educativo da escola/agrupamento. A natureza imperativa de certas medidas políticas, sobretudo aquelas que irrompem no início de cada ano letivo, exigem frequentemente uma célere implementação, mesmo que o seu espírito contrarie os princípios coletivamente assumidos pela instituição escolar. A implementação sucessiva de diplomas avulsos favorece a ocorrência de episódios de amnésia política, perdendo-se pelo caminho o sentido de missão da escola pública e as prioridades que cada escola em concreto se propôs a concretizar.

As pesquisas efetuadas revelam 0 quanto as culturas de escola condicionam o processo de produção local de política educativa (TORRES, 1997, 2004). Quanto mais forte se revela, entre os atores escolares, o sentido de pertença e a partilha da missão estratégica, maior a propensão da organização escolar para ajustar as orientações políticas à sua matriz axiológica de referência. Nesses casos, é frequente encontrarmos uma intensa produção de padrões de atuação regulados por lógicas culturais - processos de fidelização a costumes e tradições - que podem entrar em colisão com a agenda política central e, de igual forma, com a agenda política municipal. Noutros casos, em que dominam lógicas de ação mais diferenciadoras ou mesmo de sentido fragmentador, onde o sentido de missão é mais difuso e contraditório, o espaço escolar tende a ficar mais vulnerável e refém das rotas políticas centrais. Mesmo aqui, em que os mecanismos de incorporação parecem estar desvinculados da matriz cultural da escola, revela-se o peso da ação mais individual na produção de uma agenda política de terceira dimensão.

Em ambos os casos, a política em ação (ou em estado prático) está longe de corresponder aos desígnios do poder central. Desse ponto de vista, interessa indagar até que ponto a organização escolar, no exercício quotidiano do seu grau relativo de autonomia, poderá aprofundar o sentido democrático da sua missão, ajustando e recontextualizando as medidas políticas às suas singularidades culturais. No quadro de um paradigma de governação de tipo centralista, caberá às escolas e agrupamentos apesar de remetidos para uma condição periférica e implementativa (LIMA, 2011) -afirmarem-se como espaços de coconstrução política, fazendo valer o seu patrimônio simbólico-cultural no desenvolvimento de um projeto educativo próprio. Isso significa que os atores em contexto poderão orientar as suas práticas educativas por referência à identidade da instituição, fazendo desta um significativo mecanismo de regulação das diversas forças e ordens exteriores, de alcance global, nacional, regional, local e comunitário. Essa inversão da ordem regulatória, agora mais focada no dentro e no contexto de ação, poderá constituir-se - como aliás já acontece em algumas escolas do nosso país - num importante movimento de resistência ao paradigma central 
e, simultaneamente, numa oportunidade de emancipação da organização escolar.

Todavia, perante a implementação de mega-agrupamentos e, mais recentemente, de agregações de agrupamentos ${ }^{8}$, novas sinergias desafiam o métier do investigador: até que ponto o patrimônio simbólico-cultural sedimentado em cada escola subsiste à fusão organizacional? Como se articulam patrimônios distintos e por vezes rivais e conflitantes? Numa altura em que a racionalização educativa se intensifica, até que ponto o patrimônio cultural das instituições não se transformará num mero artefato de gestão?

Tomando esta última interrogação como o fio condutor deste artigo, debruçamo-nos, em seguida, sobre a análise de um ritual que tem vindo a marcar a agenda política internacional, nacional e institucional - o ritual de distinção do mérito e da excelência dos alunos nas escolas públicas - e que constitui, hoje, um dos mais importantes pilares do mandato neomeritocrático.

\section{Metodologia}

Do ponto de vista teórico, pretende-se compreender de que forma as instituições escolares definem e recontextualizam localmente as políticas educativas, tendo como referência as suas especificidades culturais. Tomando o ritual de distinção acadêmica como objeto de pesquisa empírica, procura-se indagar de que modo as organizações escolares se apropriam dessa orientação política e a põem em prática. Nesse sentido, interessa, por um lado, mapear os tipos e os mecanismos de distinção formalmente previstos nas escolas públicas e, por outro lado, identificar as especificidades organizacionais decorrentes das diferentes culturas de escola. 0 mapeamento dos rituais previstos no universo de escolas secundárias públicas permite discutir o impacto dessa orientação política na regulação

8- As agregrações de agrupamentos resultaram da fusão de agrupamentos de grandes dimensões, alguns dos quais distantes do ponto de vista geográfico. das prioridades educativas ou, por outras palavras, analisar a centralidade da cultura escolar no condicionamento das dinâmicas organizacionais. Por sua vez, a análise das práticas efetivas, por via do levantamento dos mecanismos de distinção postos em ação, remete para o processo de recontextualização cultural operado em cada escola em concreto, dando-nos pistas interpretativas sobre a cultura organizacional de escola.

Com o intuito de identificar os tipos e mecanismos de distinção formalmente previstos no universo dos estabelecimentos escolares públicos com ensino secundário em Portugal, procedeu-se, num primeiro momento, a um desenho metodológico de lógica extensiva assente na análise de conteúdo dos documentos estruturantes produzidos pelas escolas, complementada com a observação das suas páginas de internet e com a análise das notícias publicadas pela comunicação social.

Do ponto de vista da operacionalização, recorreu-se a informação disponibilizada no site da Direção Geral dos Estabelecimentos Escolares (DGEstE), tendo-se identificado 490 escolas/agrupamentos com ensino secundário em Portugal. Para efeitos de interpretação sociológica, optou-se por agrupar as escolas/ agrupamentos de Portugal Continental segundo os quadros de zona pedagógica (QZP) definidos pela Portaria n. ${ }^{\circ} 156-\mathrm{B} / 2013^{9}$. Os 490 estabelecimentos com ensino secundário distribuem-se por 261 municípios, sendo que 44,9 \% integram o QZP 1 - Braga, Viana do Castelo, Porto, Tâmega - e o QZP 7 - Lisboa, Península de Setúbal - (cf. quadro 1). Numa primeira fase, recolheram-se cerca de mil e quinhentos documentos orientadores, tendo os mesmos sido objeto de análise de conteúdo

9-0s quadros de zona pedagógica correspondem a áreas de implantação geográfica das escolas e agrupamentos de escolas com vistas à fixação de docentes por áreas geográficas. De acordo com a Portaria $n^{0} 156-$ B/2013, de 19 de abril, a criação de quadros de zona pedagógica resulta da necessidade de definir "novos espaços de dimensão geográfica que visem uma maior flexibilidade na distribuição dos docentes, garantindo melhor equilíbrio entre essa distribuição e a satisfação das necessidades das escolas, proporcionando um acréscimo de valor ao sistema educativo e a consequente melhoria dos resultados dos alunos". 
operacionalizada a partir de uma matriz de transpostos para o programa SPSS (Statistical registo em formato Excel e, posteriormente, Package for the Social Sciences).

Quadro 1 - Escolas públicas com ensino secundário por QZP e região autônoma

\begin{tabular}{l|c:c}
\hline QZP e Região Autônoma & $\mathbf{n}$ & $\%$ \\
\hline QZP 1 (Braga, V. Castelo, Porto, Tâmega) & 116 & 23,7 \\
\hline QZP 2 (Douro Sul, Vila Real, Bragança) & 39 & 8,0 \\
\hline QZP 3 (Aveiro, Entre Douro e Vouga, Viseu) & 37 & 7,6 \\
\hline QZP 4 (Coimbra, Leiria) & 38 & 7,8 \\
\hline QZP 5 (Castelo Branco, Guarda) & 28 & 5,7 \\
\hline QZP 6 (Lezíria e Médio Tejo, Oeste) & 41 & 8,4 \\
\hline QZP 7 (Lisboa, Península de Setúbal) & 104 & 21,2 \\
\hline QZP 8 (Alentejo Central, Alto Alentejo) & 20 & 4,1 \\
\hline QZP 9 (Baixo Alentejo, Alentejo Litoral) & 15 & 3,1 \\
\hline QZP 10 (Algarve) & 17 & 3,5 \\
\hline Madeira & 14 & 2,9 \\
\hline Açores & 21 & 4,3 \\
\hline Total & 490 & 100,0 \\
\hline
\end{tabular}

Num segundo momento, procedeu-se 6 e 7, num total de 247 escolas agrupadas e à análise das práticas efetivas de distinção, 53 escolas únicas de Portugal Continental, estabelecendo uma comparação com o abrangendo, ainda, a totalidade de escolas definido no plano formal-legal. Para o públicas com ensino secundário da Região efeito, selecionou-se uma amostra de 335 Autônoma da Madeira (quatorze escolas) e dos estabelecimentos (quadro 2), dos QZP 1, 2, Açores (21 escolas).

Quadro 2 - Escolas públicas com ensino secundário definidas na amostra

\begin{tabular}{|c|c|c|}
\hline QZP e Região Autônoma & $\mathrm{n}$ & $\%$ \\
\hline QZP 1 (Braga, V. Castelo, Porto, Tâmega) & 116 & 34,6 \\
\hline QZP 2 (Douro Sul, Vila Real, Bragança) & 39 & 11,6 \\
\hline QZP 6 (Lezíria e Médio Tejo, Oeste) & 41 & 12,2 \\
\hline QZP 7 (Lisboa, Península de Setúbal) & 104 & 31,0 \\
\hline Madeira & 14 & 4,2 \\
\hline Açores & 21 & 6,3 \\
\hline Total & 335 & 100,0 \\
\hline
\end{tabular}


A amostra engloba as duas regiões com o maior número de escolas públicas com ensino secundário, representando 44,9\% da totalidade dessas instituições. Abarca ainda 153 municípios, dezoito dos vinte mais populosos, para além de o âmbito geográfico das escolas concentrar 71,4\% do total da população residente em Portugal. De forma a aceder às práticas de distinção das 335 escolas/agrupamentos, analisaram-se novos documentos (quadro 3), que possibilitaram aprofundar o conhecimento das dinâmicas de premiação do mérito.

Quadro 3 - Documentos analisados segundo QZP

\begin{tabular}{|c|c|c|c|c|c|c|c|}
\hline Documentos analisados & QZP1 & QZP2 & QZP6 & QZP7 & Madeira & Açores & Total \\
\hline Regulamento Interno & 98 & 35 & 33 & 92 & 12 & 19 & 289 \\
\hline Projeto Educativo & 95 & 28 & 30 & 64 & 12 & 20 & 249 \\
\hline Relatório de Avaliação Externa & 9 & 22 & 30 & 69 & 0 & 0 & 130 \\
\hline Plano Anual de Atividades & 14 & 9 & 14 & 30 & 6 & 8 & 81 \\
\hline Projeto Curricular & 3 & 6 & 5 & 3 & 3 & 15 & 35 \\
\hline Listagem de alunos distinguidos & 20 & 5 & 13 & 40 & 1 & 4 & 83 \\
\hline $\begin{array}{l}\text { Regulamento específico sobre a instituição de } \\
\text { mecanismos de distinção }\end{array}$ & 15 & 1 & 5 & 16 & 0 & 7 & 44 \\
\hline $\begin{array}{l}\text { Documentos de publicitação de cerimônias } \\
\text { públicas }\end{array}$ & 6 & 2 & 17 & 29 & 1 & 6 & 61 \\
\hline Total & 260 & 108 & 147 & 343 & 35 & 79 & 972 \\
\hline
\end{tabular}

Fonte: Documentos orientadores (ano letivo 2013/14), sites das escolas/agrupamentos com ensino secundário, site da Inspeção Geral da Educação e Ciência e notícias publicadas na comunicação social.

\section{A consagração da distinção na agenda política da escola}

0 estudo efetuado no contexto da realidade portuguesa aponta para uma adesão significativa das instituições escolares à adoção de práticas de distinção dos melhores alunos. Apesar de esses dispositivos estarem normativamente regulamentados desde 1990 através do Decretolei n. ${ }^{\circ} 281 / 90$, de 12 de setembro, e duas décadas mais tarde consagrados como "direitos do aluno" no Estatuto do Aluno e Ética Escolar (Lei n. ${ }^{\circ}$ 51/2012, de 5 de setembro), constatou-se que nem todas as escolas $(5,9 \%)$ contemplam essas práticas nos seus documentos orientadores. Mesmo assim, é de relevar a presença desse ritual na esmagadora maioria das escolas (91,7\%), embora sob diferentes formatos e com formas de operacionalização diversas.

Da análise efetuada ao extenso corpus de informação, foi possivel identificar três tipos de distinção focados em diferentes dimensões da aprendizagem: a) nos resultados acadêmicos; b) nos valores e comportamentos; c) nos resultados e nos valores e comportamentos (distinção mista). 0 quadro 4 dá-nos conta de uma tendência clara para a valorização da distinção mista, com cerca de 70\% das escolas a inscrevêla formalmente na sua ação estratégica. Do ponto de vista formal-legal, apenas 16,5\% das escolas consagram um tipo de distinção exclusivamente centrado nos resultados.

No quadro dessas três formas de premiação do desempenho, as escolas fazem uso de diferentes mecanismos de distinção: nuns casos, reproduzindo o que está previsto nos diplomas legais; noutros casos, instituindo outras modalidades porventura mais ajustadas aos propósitos educativos da instituição. 0 quadro 5 apresenta a variedade de mecanismos existentes nas escolas consoante o tipo de distinção previsto. Constata-se a 
preferência pela implementação dos quadros de excelência (focados na média ponderada das classificações internas obtidas nas várias disciplinas) combinados com os quadros de valor (focados nos comportamentos e atitudes), o que configura a distinção mista. De notar que o critério mais utilizado para a integração dos alunos no quadro de excelência consiste na obtenção de classificações internas superiores a 17,5 valores, muito embora, do ponto de vista formal-legal, a condição mínima de candidatura esteja fixada em 16 valores (Despacho Normativo n ${ }^{\circ}$ 102/90, artigo $5^{\circ}$, ponto 5 ).

Quadro 4 - Tipo de distinção formalmente previsto

\begin{tabular}{|c|c|c|}
\hline Tipos de distinção & $\mathrm{N}$ & $\%$ \\
\hline Distinção focada exclusivamente nos resultados & 81 & 16,5 \\
\hline Distinção focada exclusivamente nos valores/comportamentos & 7 & 1,4 \\
\hline Distinção mista (resultados e valores/comportamentos) & 361 & 73,7 \\
\hline Sem distinção & 29 & 5,9 \\
\hline Sem Informação & 12 & 2,4 \\
\hline Total & 490 & 100,0 \\
\hline
\end{tabular}

Fonte: Documentos orientadores das escolas/agrupamentos com ensino secundário (ano letivo 2013/14).

Quadro 5 - Mecanismos de distinção formalmente previstos

\begin{tabular}{|c|c|c|}
\hline Tipos de distinção & Mecanismos de distinção & $\%$ \\
\hline Distinção focada nos resultados & $\begin{array}{l}\text { Quadro de excelência/mérito/honra } \\
\text { Prêmios de mérito } \\
\text { Bolsas/diplomas de mérito, louvor de mérito }\end{array}$ & $\begin{array}{l}8,0 \% \\
6,4 \% \\
3,5 \%\end{array}$ \\
\hline Distinção focada nos valores & Quadro de valor, título de mérito & $1,5 \%$ \\
\hline Distinção mista & $\begin{array}{l}\text { Quadro de excelência + quadro de valor } \\
\text { Prêmio de mérito misto } \\
\text { Bolsas de mérito + diplomas de mérito }\end{array}$ & $\begin{array}{l}51,6 \% \\
16,9 \% \\
12,6 \%\end{array}$ \\
\hline
\end{tabular}

Fonte: Documentos orientadores das escolas/agrupamentos com ensino secundário (ano letivo 2013/14).

A análise da informação contida nos portais eletrônicos das escolas ajudou a compreender a importância institucional conferida às práticas de distinção, deduzida a partir da sua presença e destaque em termos de divulgação pública. Assim, do total das escolas que aderiram formalmente a essa prática, cerca de 40,3\% publicitou-a de forma explícita no seu portal, em muitos casos em lugar de destaque e a figurar por longo tempo nas novidades.

A grande maioria das escolas que implementa práticas de distinção realiza uma cerimônia pública de entrega de prêmios e diplomas (83\%), com a presença dos alunos, dos pais e encarregados de educação, dos representantes da comunidade local e, em muitos casos, dos órgãos de comunicação social. Apesar de o ritual obedecer, regra geral, ao mesmo formato, a carga simbólica conferida pela comunidade escolar a esse momento difere, podendo o mesmo tanto ser remetido para o final de um dia de aulas quanto ser estrategicamente realizado durante um dia inteiro, enquadrado em eventos e iniciativas várias e culminando com o ato solene de entrega dos prêmios ou diplomas aos melhores alunos. 


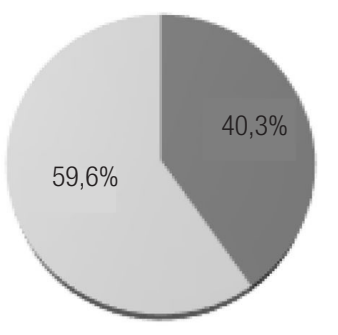

- Sim Não

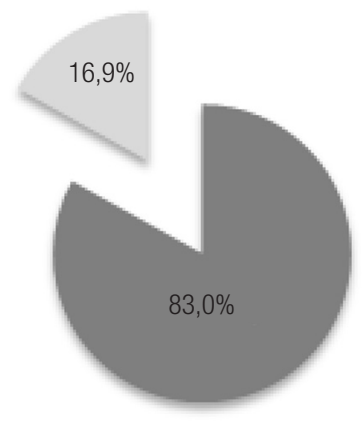

- Sim Não

Fonte: Documentos orientadores (ano letivo 2013/14), sites das escolas/agrupamentos com ensino secundário e notícias publicadas na comunicação social.

Numa primeira leitura, a ampla adesão das escolas às práticas de distinção do mérito aponta para a reprodução da cultura escolar, de tipo marcadamente performativo, difundida à escala nacional através de diferentes dispositivos formais-legais. A consagração, no plano discursivo, da distinção mista traduz a preocupação em conciliar os objetivos da excelência e inclusão, ao prever a dupla premiação, dos resultados e dos comportamentos exemplares. A publicitação e cerimonialização desse ritual contribui, naturalmente, para reforçar o projeto socializador da escola, marcando de forma significativa as suas prioridades. Mas, será essa cultura escolar apropriada de forma similar nas diferentes regiões do país e nos diversos contextos escolares?

0 gráfico 4 apresenta o mapeamento nacional das práticas de distinção, mostrando a sua presença nas diferentes zonas pedagógicas, assim como nas regiões autônomas da Madeira e dos Açores. Algumas tendências gerais merecem registo: a) a ausência de assimetrias regionais de relevo; b) a presença expressiva dessa prática de norte a sul do país, com valores acima dos 94\% na Madeira, na região norte e centro interior, nas zonas do Alto Alentejo, em Lisboa e no Algarve; c) a menor adesão aos mecanismos de distinção na região do Baixo Alentejo e Alentejo Litoral.

Gráfico 4 - Mecanismos de distinção previstos nos documentos orientadores

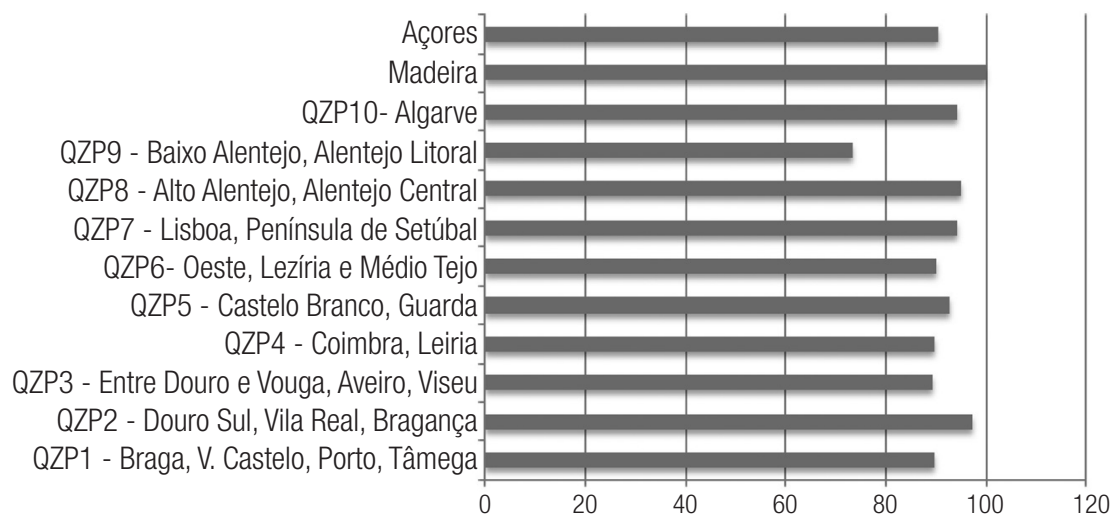

Fonte: Documentos orientadores das escolas/agrupamentos com ensino secundário (ano letivo 2013/14). 
Ainda na rota das tendências gerais, o gráfico 5 ilustra a predominância da distinção mista como a prática mais utilizada nas escolas e agrupamentos localizados nas várias regiões do país. Contudo, algumas especificidades regionais apontam para fenômenos sociologicamente interessantes: a) um maior peso da distinção centrada nos resultados na Madeira (50\%), na região do Norte Interior (28,2\%), no Centro
Litoral (19\%) e na região Norte Litoral (18,1\%); b) a distinção nos valores apenas presente na região do Alto Alentejo e Alentejo Central (15\%) e residualmente na zona Centro Litoral (3\%), no Oeste, Lezíria e Médio Tejo (2\%) e Norte Litoral (2\%); c) a região de Baixo Alentejo e Alentejo Litoral com a percentagem mais elevada de escolas e agrupamentos sem mecanismos de distinção (13\%).

Gráfico 5 - Tipo de distinção por QZP

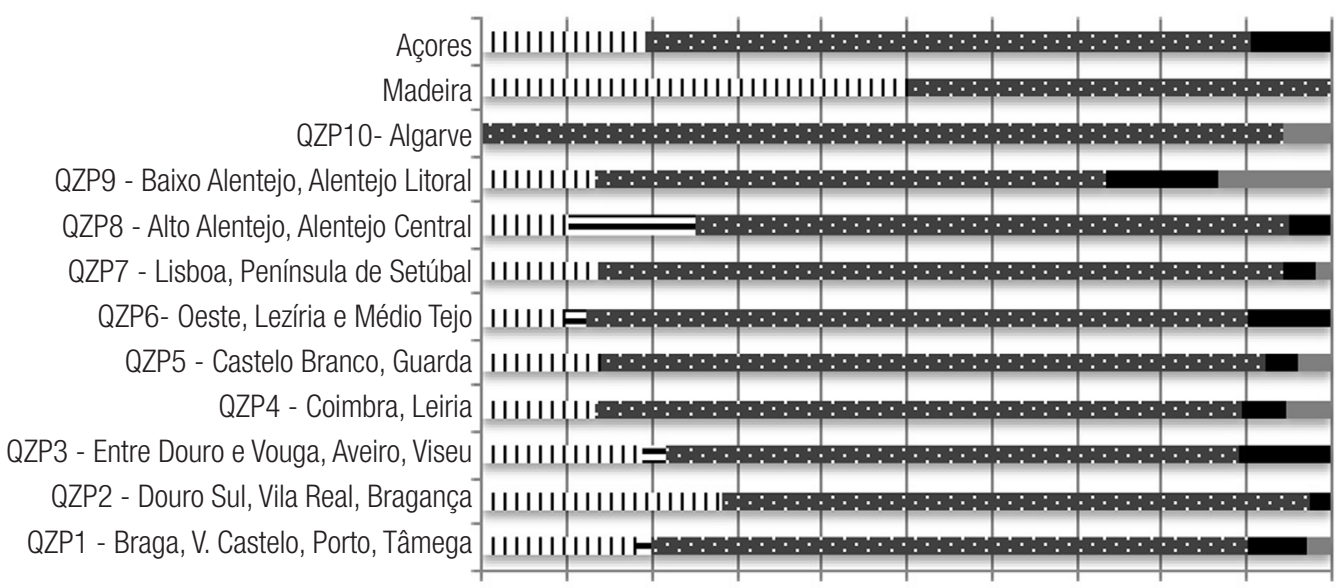

II Distinção focada nos resultados
- Distinção mista
- Sem informação

= Distinção focada nos valores

- Sem Distinção

Fonte: Documentos orientadores das escolas/agrupamentos com ensino secundário (ano letivo 2013/14).

Do ponto de vista da importância conferida a essas práticas, traduzida parcialmente pelos indicadores de publicitação no site da escola e pela realização de uma cerimônia pública, também se vislumbram alguns padrões e singularidades, sinalizados no quadro 6. Em primeiro lugar, não se encontra qualquer relação entre o tipo e incidência da distinção e a propensão para a divulgação e realização de cerimônia pública. Por exemplo, as regiões que mais publicitam o ritual (QZP1, QZP4 e QZP9) apresentam um padrão de distinção próximo das tendências nacionais. Por sua vez, a Madeira, onde a totalidade das escolas implementa práticas de premiação (50\% focadas nos resultados) é uma das regiões que menos as publicita. Em segundo lugar, a esmagadora maioria das organizações prevê a realização de cerimônia pública, embora, nas regiões adstritas ao QZP4, QZP5 e QZP9, a sua frequência seja mais baixa.

Apesar de ser precoce aventar explicações conclusivas, é possível arriscar algumas pistas explicativas que ajudem a compreender as especificidades regionais: com a exceção da região autônoma da Madeira, cujo enquadramento legal e cultural é diferente daquele do Continente, a ênfase colocada nos 
Quadro 6 - Divulgação e cerimonialização da distinção por região

\begin{tabular}{|c|c|c|c|}
\hline QZP & Escolas com distinção (\%) & $\begin{array}{c}\text { Publicitação na página eletrônica } \\
\text { (\%) }\end{array}$ & $\begin{array}{l}\text { Realização de cerimônia pública } \\
\text { (\%) }\end{array}$ \\
\hline QZP1 & 89,7 & 50 & 92,3 \\
\hline QZP2 & 97,4 & 34,2 & 81,6 \\
\hline QZP3 & 89,2 & 42,4 & 78,7 \\
\hline QZP4 & 89,5 & 44,1 & 47,0 \\
\hline QZP5 & 92,8 & 19,2 & 61,5 \\
\hline QZP6 & 90,2 & 43,2 & 91,9 \\
\hline QZP7 & 94,2 & 41,8 & 83,7 \\
\hline QZP8 & 95 & 36,8 & 89,5 \\
\hline QZP9 & 73,3 & 45,5 & 63,6 \\
\hline QZP10 & 94,1 & 37,5 & 81,3 \\
\hline Madeira & 100 & 21,4 & 100 \\
\hline Açores & 90,5 & 15,8 & 89,5 \\
\hline
\end{tabular}

Fonte: Documentos orientadores das escolas/agrupamentos com ensino secundário (ano letivo 2013/14).

resultados na região nordeste poderá estar relacionada com o posicionamento menos positivo dessas escolas no ranking nacional e, igualmente, com a necessidade de resistir ao movimento em curso de encerramento de escolas nessa zona do país; por outro lado, a valorização da distinção focada nos valores na região do Alentejo poderá significar a centralidade atribuída aos valores inclusivos, mais próximos das necessidades educativas da região, cujas taxas de abandono e insucesso são significativas ${ }^{10}$.

Num exercício ainda bastante exploratório, o quadro 7 sinaliza algumas nuances entre as regiões: a omnipresença do tipo de distinção mista, à qual surge agregado, nas regiões Norte, Centro e Ilhas, o enfoque

10 - Os fenômenos de desertificação, envelhecimento da população e queda da natalidade verificados na região do Alentejo constituem fatores importantes para compreender a natureza dos problemas enfrentados pelas instituições escolares e, em articulação, a necessidade de essas organizações ajustarem a sua missão à realidade social e cultural envolvente. As elevadas taxas de abandono e insucesso escolar exigem, porventura, uma focagem prioritária na inclusão e integração das crianças e jovens, em detrimento de um investimento centrado nos resultados. nos resultados; a transversalidade regional de elevados níveis de previsão da distinção; o fraco investimento, por parte das escolas de todo o território nacional, na publicitação dessas distinções, em contraste com uma forte aposta na cerimonialização; a concentração regional, entre a capital e o Norte do país, das escolas com bom e muito bom desempenho no ranking; a inexistência de relação linear entre este posicionamento no ranking e os tipos de distinção, frequência da publicitação e cerimonialização desses rituais de distinção.

\section{As práticas de distinção do mérito}

0 confronto entre o plano das orientações (tipo de distinção formalmente previsto) e o plano das realizações (prática de distinção efetiva) mostrou, entretanto, uma clara não coincidência, reveladora do processo de mediação não linear entre a ordem política central e global (primeira dimensão - cultura 
Quadro 7 - Caracterização da distinção por região

\begin{tabular}{c|c|c|c|c|c} 
& Previsão de distinção (1) & Tipo de distinção & Publicitação (2) & Cerimônia (3) & Ranking (4) \\
\hline Norte & Muito elevada & Mista + Resultados & Média + Baixa & Muito frequente & Bom (22,6\%) \\
\hline Centro & Muito elevada & Mista + Resultados & Muito baixa & Frequente & Muito Bom (33\%) \\
\hline Lisboa & Muito elevada & Mista & Baixa & Muito frequente & Bom (26,5\%) \\
\hline Alentejo & Elevada & Mista + Valores & Baixa & Frequente & Suficiente (11,4\%) \\
\hline Sul & Muito elevada & Mista & Muito baixa & Muito frequente & Insuficiente $(6,3 \%)$ \\
\hline Ilhas & Muito elevada & Mista + Resultados & Muito baixa & Quase sempre & Suficiente $(11,4)$ \\
\hline
\end{tabular}

(1) Muito elevada: superior a 90\%; Elevada: superior a 80\%; Média: superior a $60 \%$

(2) Média: superior a 50\%; Baixa: superior a 40\%; Muito baixa: superior a $20 \%$

(3) Quase sempre: superior a 90\%; Muito frequente: superior a 80\%; Frequente: superior a $60 \%$

(4) Muito Bom: mais de 30\% das escolas nos primeiros 200 lugares; Bom: mais de 20\% das escolas nos primeiros 200 lugares; Suficiente: 10\% das escolas nos primeiros 200 lugares; Insuficiente: abaixo de 10\% das escolas nos primeiros 200 lugares.

escolar), a recepção em contexto organizacional (segunda dimensão - cultura organizacional escolar) e a recontextualização no espaço social da instituição (terceira dimensão - cultura organizacional de escola).

Os dados apresentados no quadro 8 expressam, na sua globalidade, a preferência das escolas pela distinção focada nos resultados acadêmicos e a desvalorização da distinção mista. Algumas tendências merecem destaque: a) a percentagem de escolas/agrupamentos que na prática efetiva implementam uma distinção de resultados e valores é de $39,4 \%$ (substancialmente inferior à que foi identificada no plano formal, 73,4\%); b) 48,1\% das escolas/agrupamentos distingue os alunos exclusivamente pelos resultados acadêmicos, uma percentagem substancialmente diferente das 18,2\% que o afirmavam nos seus documentos orientadores; c) 2,4\% não implementa nenhum tipo de distinção, um valor superior em relação ao formalmente previsto $(1,8 \%)$.

Quadro 8 - Comparação entre distinção prevista e distinção praticada

\begin{tabular}{|c|c|c|c|c|}
\hline \multirow{2}{*}{ Tipo de distinção } & \multicolumn{2}{|c|}{ Distinção prevista } & \multicolumn{2}{|c|}{ Distinção praticada } \\
\hline & $\mathrm{n}$ & $(\%)$ & $\mathrm{n}$ & $(\%)$ \\
\hline Distinção focada exclusivamente nos resultados & 61 & 18,2 & 161 & 48,1 \\
\hline Distinção focada exclusivamente nos valores & 3 & 0,9 & 4 & 1,2 \\
\hline Distinção mista & 246 & 73,4 & 132 & 39,4 \\
\hline Sem distinção & 19 & 5,7 & 30 & 9,0 \\
\hline Sem Informação & 6 & 1,8 & 8 & 2,4 \\
\hline Total & 335 & 100 & 335 & 100 \\
\hline
\end{tabular}

Fonte: Documentos orientadores (ano letivo 2013/2014), sites das escolas/agrupamentos com ensino secundário, notícias publicadas na comunicação social, relatórios de avaliação externa e outros documentos. 
Efetivamente, os dados mostram que o critério meritocrático, estritamente associado aos resultados acadêmicos, predomina nas práticas de distinção, reforçando o diagnóstico de Ball (2002, p. 15) quando afirma que "As exigências da performatividade impedem dramaticamente os 'discursos metafísicos', o relacionamento da prática com princípios filosóficos, como justiça social e equidade". Numa sociedade cada vez mais performativa, também na educação, a produção de resultados e a sua medição são peças basilares, refletindo-se no tipo de distinção implementado pelas escolas/ agrupamentos e na desvalorização da distinção de valores e comportamentos dos alunos. Constata-se que, dos 335 estabelecimentos escolares analisados, apenas $4(1,2 \%)$ implementam uma distinção focada exclusivamente nos valores/comportamentos dos alunos. 0 direito de o aluno ver reconhecido o "empenhamento em ações meritórias, designadamente o voluntariado em favor da comunidade em que está inserido ou da sociedade em geral, praticadas na escola ou fora dela, e ser estimulado nesse sentido" (Lei n. ${ }^{\circ}$ 51, 2012) encontra-se posto em causa por uma performatividade competitiva que assola o campo educativo.

Se, por um lado, os resultados mostram uma elevada adesão das escolas aos rituais de consagração do mérito, por outro, revelam algumas especificidades regionais evidenciadas no quadro 9. Em primeiro lugar, a região da Madeira destaca-se pela prática de distinções centradas nos resultados (85,7\%), com uma variação positiva de 35,7\% em relação ao formalmente previsto (50,0\%), logo seguida da região Norte $(52,6 \%)$, com uma variação positiva de 34,5\% em relação ao formalmente previsto (18,1\%). Em segundo lugar, a capital (Lisboa) sobressai como a região onde a distinção mista $(40,4 \%)$ apresenta uma variação negativa de 40,4\% em relação ao formalmente previsto $(80,8 \%)$, sendo a região com a maior diferença entre o instituído e o implementado respeitante a esse tipo de distinção. Em terceiro lugar, regista-se a distinção mista nas escolas/ agrupamentos que integram o QZP 6 (61,0\%), com uma variação negativa de apenas 17\% em relação ao formalmente previsto $(78,0 \%)$, sendo a região onde mais se privilegia (em nível formal e da sua implementação) a distinção de resultados e valores/comportamentos. Por último, destaque para a percentagem de escolas/ agrupamentos que integram o QZP2 que não implementam nenhuma distinção $(15,4 \%)$, sendo a região onde a preponderância sem distinção é mais elevada e mais contraditória em relação ao formalmente previsto $(2,6 \%)$.

Quadro 9 - Distinção prevista e implementada, segundo a região

\begin{tabular}{|c|c|c|c|c|c|c|c|}
\hline & Tipo de distinção & QZP1 (\%) & QZP2 (\%) & QZP6 (\%) & QZP7 (\%) & Madeira (\%) & Açores (\%) \\
\hline \multirow{5}{*}{ Previsto } & Exclusivamente nos resultados & 18,1 & 28,2 & 9,8 & 13,5 & 50,0 & 19,0 \\
\hline & Exclusivamente nos valores & 1,7 & 0,0 & 2,4 & 0,0 & 0,0 & 0,0 \\
\hline & Distinção mista & 69,8 & 69,2 & 78,0 & 80,8 & 50,0 & 71,4 \\
\hline & Sem distinção & 6,9 & 2,6 & 9,8 & 3,8 & 0,0 & 9,5 \\
\hline & Sem Informação & 3,4 & 0,0 & 0,0 & 1,9 & 0,0 & 0,0 \\
\hline \multirow{5}{*}{ Implementado } & Exclusivamente nos resultados & 52,6 & 46,2 & 34,1 & 44,2 & 85,7 & 47,6 \\
\hline & Exclusivamente nos valores & 2,6 & 0,0 & 2,4 & 0,0 & 0,0 & 0,0 \\
\hline & Distinção mista & 33,6 & 38,5 & 61,0 & 40,4 & 14,3 & 42,9 \\
\hline & Sem distinção & 7,8 & 15,4 & 2,4 & 11,5 & 0,0 & 9,5 \\
\hline & Sem Informação & 3,4 & 0,0 & 0,0 & 3,8 & 0,0 & 0,0 \\
\hline
\end{tabular}

Fonte: Documentos orientadores (ano letivo 2013/2014), sites das escolas/agrupamentos com ensino secundário, notícias publicadas na comunicação social, relatórios de avaliação externa e outros documentos. 
Em síntese, depreende-se a existência de singularidades regionais relativamente às práticas de premiação, cuja interpretação exigirá, nos tempos próximos, uma análise mais aprofundada. Porém, não deixa de ser curioso observar uma certa afinidade entre o tipo de distinção praticado e a filiação político-partidária dos municípios: as regiões que mais aderem à distinção focada nos resultados parecem ser aquelas cujos municípios são maioritariamente de direita (PSD/CDS); a distinção focada nos valores incide mais nas regiões cujas autarquias são de esquerda (PS/CDU/BE). Essa hipótese de trabalho, a desenvolver no futuro, poderá ajudar a compreender os sentidos de apropriação da ideologia meritocrática e a força que os municípios vêm adquirindo na regulação cultural das escolas.

\section{Consideraçōes finais}

0 mapeamento dos rituais de distinção dos melhores alunos em Portugal permitiu pôr em evidência a afırmação da cultura meritocrática na agenda política das instituições escolares, refletindo claramente as orientações de política educativa nacional e internacional (TORRES; QUARESMA, 2014). A valorização crescente de uma cultura performativa, reforçada por variados dispositivos de controle e prestação contas, constitui hoje um pilar estruturante da cultura escolar. Mesmo que subsista, contraditoriamente, a retórica da inclusão e equidade, bem expressa nos preâmbulos dos diplomas legais que regulam o funcionamento do sistema escolar, é cada vez mais onipresente a força dos mecanismos de controle e de prestação de contas, que, na prática, impõem uma ordem centrada na produção de resultados. Esse pilar de natureza resultadista, sustentado em diversas exigências de tipo avaliativo e inspetivo, empurra as escolas para uma nova lógica de funcionamento sobredeterminada pelas instâncias centrais e locais. Essa realidade apresenta algumas similitudes com o diagnóstico traçado na obra recentemente publicada Governing by inspection (GREC; LINDGREN, 2014), a propósito das práticas de governação da educação no espaço europeu.

Num primeiro nível de análise, os resultados demonstram a adesão da esmagadora maioria das escolas/agrupamentos do ensino secundário a práticas de distinção dos melhores alunos, reproduzindo, grosso modo, a orientação global. Contudo, quando se encaminha a análise para o domínio das práticas organizacionais, procurando aceder à política em estado prático, constatam-se alguns desvios em relação à rota formalmente prevista. Nesse patamar de análise, interessa destacar a crescente centralidade do poder local no condicionamento das políticas desenvolvidas nas escolas, agora mais alinhadas com os projetos educativos municipais e com as orientações recebidas no Conselho Municipal de Educação. A progressiva transferência de competências de gestão educativa para as autarquias constitui um fator relevante a ter em consideração na construção da cultura organizacional escolar. Mais dependentes das políticas locais, as escolas e agrupamentos tendem a recontextualizar-se, ajustando as suas práticas às diretrizes (político-ideológicas) dominantes.

Procurando mobilizar o modelo analítico (gráfico 1) para a interpretação dos resultados, a consagração formal de distinções de tipo misto denuncia o tipo de apropriação organizacional verificada na maioria das escolas para responder aos imperativos globais. Assim, a generalidade das escolas considerou importante plasmar, nos seus documentos orientadores, a premiação dos resultados e dos comportamentos dos alunos, combinando duas variantes da missão da escola: a excelência e a inclusão. Essa apropriação aparentemente linear apresenta, porém, algumas diferenciações consoante a região, exigindo, do ponto de vista analítico, o recurso à segunda dimensão - cultura organizacional escolar. A forma como cada escola em concreto definiu as estratégias de premiação, enveredando por diferentes mecanismos de distinção, resultou certamente de ajustamentos sucessivos à realidade organizacional das escolas e do seu 
alinhamento com as orientações políticas locais. Todavia, interessa além do plano retórico e perceber de que forma as escolas operacionalizam na ação esses dispositivos de distinção. Os resultados são esclarecedores a esse respeito, ao subentenderem a presença de uma terceira dimensão - cultura organizacional de escola, que aponta para uma realidade escolar mais plural, mas também mais rendida ao culto da performatividade. No plano da ação, depreende-se a coexistência de variados mecanismos de premiação e de publicitação das celebrações, consoante a identidade da instituição. $\mathrm{Ou}$ seja, no exercício da sua autonomia relativa, os atores escolares agem por referência ao patrimônio cultural instituído, daqui resultando apropriações diversas da agenda meritocrática, quer ela seja de âmbito (trans)nacional, quer seja reforçada em nível local, quer esteja inscrita na estratégia da instituição. As singularidades encontradas em nível regional denunciam a presença de variados fatores no desenvolvimento das políticas em ação, externos e internos à instituição escolar: filiação político-ideológica dos municípios, condições sociais, demográficas e econômicas das regiões, grau de competitividade entre escolas e agrupamentos, o enraizamento da matriz identitária das escolas, entre outros fatores relevantes. Mas o que ressalta com mais evidência são os desvios das escolas às rotas formalmente previstas nos seus projetos educativos, o que pode significar a incorporação do ideário meritocrático, sobretudo por parte dos líderes escolares, responsáveis pela gestão da performance. A confirmar-se essa hipótese, o patrimônio cultural das instituições poderá, de fato, estar a transformar-se num mero artefato de gestão ao serviço dos imperativos globais.

\section{Referências}

AFONSO, Almerindo. Estratégias e percursos educacionais: das explicações às novas vantagens competitivas da classe média. In: COSTA, Jorge A.; NETO-MENDES, António; VENTURA, Alexandre (Orgs.). Xplica internacional: panorâmica sobre o mercado das explicações. Aveiro: Universidade de Aveiro, 2013. p. 167-188.

ALVESSON, Mats. Understanding organizational culture. London: Sage, 2002.

ALVESSON, Mats; BERG, Per Olof. Corporate culture and organizational symbolism: an overview. Berlin; New York: Walter de Gruyter, 1992.

BALL, Stephen J. Reformar escolas/reformar professores e os terrores da performatividade. Revista Portuguesa de Educação, Braga, v. 15, n. 2, p. 3-23, 2002.

BARROSO, João. A investigação sobre a regulação das políticas públicas de educação em Portugal. In: BARROSO, João (Org.). A regulação das políticas públicas de educação: espaços, dinâmicas e actores. Lisboa: Educa, 2006. p. 42-70.

BARROSO, João. 0 Estado, a educação e a regulação das políticas públicas. Educação e Sociedade, Campinas, v. 26, n. 92, p. 725-751, out. 2005.

BARROSO, João. Regulação e desregulação nas políticas educativas: tendências emergentes em estudos de educação comparada. In: BARROSO, João (Org.). A escola pública: regulação, desregulação, privatização. Porto: ASA, 2003. p. 19-48.

BARROSO, João; CARVALHO, Luís M. (Eds.). Knowledge and regulatory processes in health and education policies. Lisboa: Educa, 2012.

BAUDELOT, Christian; ESTABLET, Roger. L'élitisme républicain: l'école française à l'épreuve des comparaisons internationales. Paris: Éditions du Seuil, 2009.

BRANDEN, Kris; AVERMAET, Piet; HOUTTE, Mieke (Eds.). Equity and excellence: towards maximal learning. Opportunities for all students. New York: Routledge, 2011. 
CARVALHO, Luís M. (Coord.). 0 espelho perito: inquéritos internacionais, conhecimento e política em educação - 0 caso PISA. Vila Nova de Famalicão: Fundação Manuel Leão, 2011.

CUNHA, Pedro d'Orey. Excelência e qualidade em educação. In: CUNHA, Pedro d'Orey (Coord.). Educação em debate. Lisboa: Universidade Católica, 1997. p. 83-11.

DURU-BELLAT, Marie. Le mérite contre la justice. Paris: Presses de Sciences Po, 2009.

DURU-BELLAT, Marie. L'inflation scolaire: les désillusions de la méritocratie. Paris: Éditions du Seuil, 2006.

DUBET, François. Les places et les chances: repenser la justice sociale. Paris: Éditions du Seuil, 2010.

GREC, Sotiria; LINDGREN, Joakim (Eds.). Governing by inspection. London: Routledge, 2014.

HIRTT, Nico. Les nouveaux maîtres de l'école: l'enseignement européen sous la coupe des marchés. Paris: Aden Asbl, 2005.

LAVAL, Christian. L'école n'est pas une entreprise: le néo-libéralisme à l'assaut de l'enseignement public. Paris: La Découverte, 2004.

LIMA, Licínio C. Elementos de hiperburocratização da administração educacional. In: LUCENA, Carlos; SILVA JÚNIOR, João dos Reis (Orgs.). Trabalho e educação no século XXI: experiências internacionais. São Paulo: Xamã, 2012. p. 129-158.

LUCENA, Carlos; SILVA JÚNIOR, João dos Reis. Administração escolar: estudos. Porto: Porto Editora, 2011.

MARTIN, Joanne. Cultures in organizations: three perspectives. Oxford: Oxford University Press; London: Sage Publications, 1992. p. 58-76.

MARTIN, Joanne. Organizational culture: mapping the terrain. London: Sage Publications, 2002.

PROSSER, Jon. The evolution of school culture research. In: PROSSER, Jon (Ed.). School culture. London: Sage, 1999. p. 1-14.

SCHEIN, Edgar H. Organizational culture and leadership. São Francisco: Jossey-Bass, 1985.

SCHEIN, Edgar H. The role of the founder in the creation of organizational culture. IN: FROST, Peter J. Frost et al. (Eds.). Reframing organizational culture. London: Sage, 1991. p. 14-25.

TORRES, Leonor L. Cultura organizacional em contexto educativo: sedimentos culturais e processos de construção do simbólico numa escola secundária. Braga: Centro de Investigação em Educação da Universidade do Minho, 2004.

TORRES, Leonor L. Cultura organizacional em contexto escolar. In: LIMA, Licínio C. (Org.). Perspectivas de análise organizacional das escolas. Vila Nova de Gaia: Fundação Manuel Leão, 2010. p. 109-152.

TORRES, Leonor L. Cultura organizacional escolar: representações dos professores numa escola portuguesa. Oeiras: Celta, 1997.

TORRES, Leonor L.; PALHARES, José A. (Orgs.). Entre mais e melhor escola em democracia: a inclusão e a excelência no sistema educativo português. Lisboa: Mundos Sociais, 2014.

TORRES, Leonor L.; QUARESMA, Luísa. Configurações da distinção escolar nos planos nacional e internacional. In: Colóquio Luso-Brasileiro de Sociologia da Educação, 4., 2014, Porto. Entre crise e euforia: práticas e políticas educativas no Brasil e em Portugal. Porto: FLUP, no prelo. E-book.

VAN ZANTEN, Agnès. Choisir son école: stratégies familiales et médiations locales. Paris: PUF, 2009.

VAN ZANTEN, Agnès (Dir.). L'école, l'état des savoirs. Paris: La Découverte, 2000.

Recebido em: 18.11.2014

Aprovado em: 11.03.2015

Leonor Lima Torres é docente na Universidade de Minho, Portugal. 